\title{
Study on the thermal properties of poly(vinyl alcohol) in the presence of collagen
}

\author{
(INDEX: 111-116/2010 Copernican Letters ${ }^{\circledR}{ }^{\circ o l} 1$ ) \\ Alina Sionkowska*, Anna Płanecka, Justyna Kozłowska, Joanna Skopińska-Wiśniewska \\ Book Faculty of Chemistry, N. Copernicus University, Gagarin 7, 87-100 Torun, Poland
}

Corresponding author: A. Sionkowska, email: as@chem.uni.torun.pl

\begin{abstract}
Crystallization of poly(vinyl alkohol) (PVA) in the presence of $1 \%, 3 \%$ and $5 \%$ of collagen has been studied by Differential Scanning Calorimetry (DSC). PVA samples containing $1 \%, 3 \%$ and $5 \%$ of collagen after melting were crystallized with different cooling rate.

The melting temperature of poly(vinyl alcohol) PVA in the presence of $1 \%, 3 \%$ and $5 \%$ of collagen is little big bigger than that for pure PVA. Small amount of collagen in PVA increases melting temperature probably due to hydrogen bonding between PVA and collagen. Collagen contains several side groups capable to form hydrogen bonds with $\mathrm{OH}$ group of PVA.

The amount of crystallinity in PVA containing $1 \%$, $3 \%$ and $5 \%$ of collagen is little big smaller than for pure PVA. Small amount of collagen in PVA causes disorder between polymer chains of polymer and leads to decrease of crystallinity. Crystallization process occurs slower in PVA containing small amount of collagen than for pure melt PVA.
\end{abstract}

\section{Introduction}

The thermal degradation of poly(vinyl alcohol) (PVA) has been studied by several researchers [1-4]. Thermal degradation of PVA in a solid state was considered to be due to the elimination of hydroxyl side groups. In the molten state thermal degradation leads to the production of volatile saturated and unsaturated aldehydes and ketones [1]. PVA is a widely used synthetic biomaterial and for this reason not only thermal degradation is very important but also the melting point of this polymer seems to be very important [5]. Sometimes it is very important to improve biocompatibility and/or surface properties of PVA. For this reason a small amount of natural polymer can be added to PVA.
Several natural polymers like starch [6], collagen [7,8], chitosan [9], silk [10] and lignin [11] have been already used to prepare PVA blends.

Polymeric materials based on PVA are often treated by high temperature during the sterilization of biomaterial.

Thermal stability of PVA can be modified by small addition of other polymers and/or biopolymers. In our study for modification of thermal stability of PVA we used small amount of collagen.

Collagen is a biopolymer, the most abundant protein in animals organisms where it provides the principal structural and mechanical support $[12,13]$.

The aim of this work was to study the thermal properties of PVA in the presence of small amount of collagen $(1 \%, 3 \%$ and $5 \%)$.

\section{Materials and methods}

PVA was obtained from Fluka $(90.98 \%$ degree of hydrolysis). Collagen was obtained in our laboratory from tail tendons of young albino rats. Polymer blends were prepared by mixing suitable volumes of collagen and PVA aqueous solution and the final amount of collagen in PVA was $1 \%$, $3 \%$ and $5 \%$ (by weight). Polymer films were obtained by casting solution onto glass plate. After solvent evaporation, the samples were dried in vacuum at room temperature.

Differential Scanning Calorimetry DSC measurements were performed using the 
TA instrument Modulated 2930 at a rate of $10^{\circ} \mathrm{C} / \mathrm{min}$ from 0 to $250^{\circ} \mathrm{C}$. DSC curves for each film were obtained from the first heating run. In order to assess the crystallization temperature the specimens were heated with different rates $\left(200^{\circ} \mathrm{C} / \mathrm{min}, \quad 100^{\circ} \mathrm{C} / \mathrm{min}, \quad 50^{\circ} \mathrm{C} / \mathrm{min}\right.$, $20^{\circ} \mathrm{C} / \mathrm{min}$ ) to melt PVA films and later on they were cooled with the same rate to crystallize the polymer. The weight of each sample film was about $5 \mathrm{mg}$.

\section{Results and discussion}

PVA films used in this study were analysed by DSC. DSC curves for PVA film and PVA films containing collagen are presented in Figures 1.

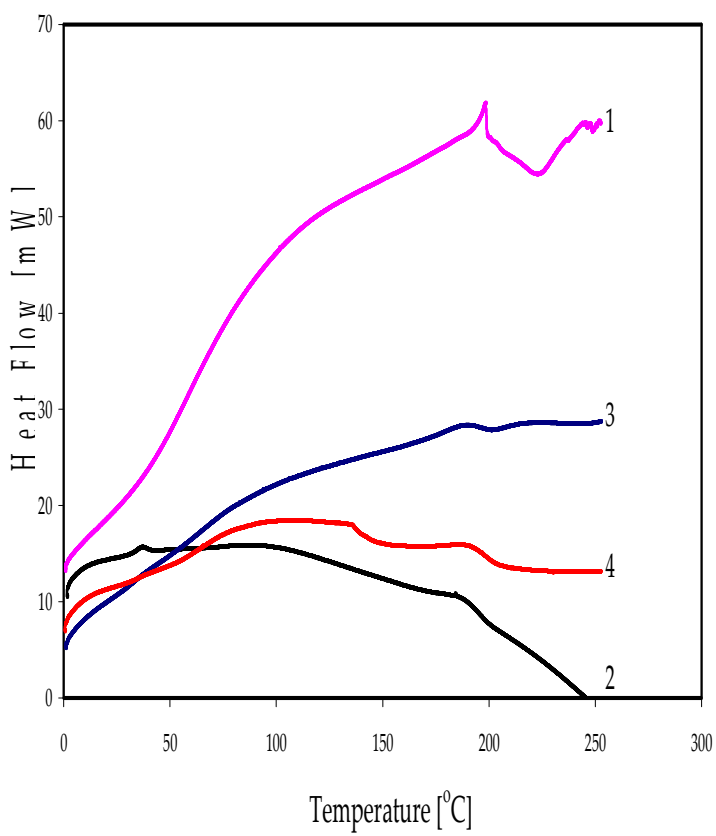

Fig. 1. DSC curves of PVA films, collagen films and PVA containing collagen (1- collagen, 2- PVA, 3- PVA $+3 \%$ collagen, 4 - PVA+5\% collagen)

For pure PVA we observe a peak of melting temperature at $184^{\circ} \mathrm{C}$. A glass transition temperature was not observe. The value of melting point depends on the degree of crystalline phase in PVA film and on water amount in PVA film. For highly crystalline PVA the melting point is about $230^{\circ} \mathrm{C}$ [1]. The melting point of PVA used in our study was below $200^{\circ} \mathrm{C}$ and suggests that PVA in thin film is not highly crystalline. We observed that the thermal stability of PVA is different when PVA contains $1 \%, 3 \%$ and $5 \%$ of collagen (Figures 1, Table 1).

Table 1

Melting temperature of PVA and PVA containing $1 \%, 3 \%$ and $5 \%$ of collagen

\begin{tabular}{|l|l|}
\hline Specimen & $\mathrm{T}_{\mathrm{m}}\left[{ }^{\circ} \mathrm{C}\right]$ \\
\hline $\mathrm{PVA}$ & 184 \\
\hline $\mathrm{PVA}+1 \%$ collagen & 187 \\
\hline PVA $+3 \%$ collagen & 187 \\
\hline PVA+ 5\% collagen & 189 \\
\hline Collagen & 198 \\
\hline
\end{tabular}

In the presence of small amount of collagen the melting temperature of PVA slightly increases probably due to hydrogen bonding between PVA and collagen. Collagen contains several side groups capable to form hydrogen bonds with $\mathrm{OH}$ group of PVA.

In the Table 2 we compare the area of crystalline melting peak, $(\Delta \mathrm{H})$ for PVA films and PVA containing collagen. One can see that for PVA containing collagen the area of melting curve is smaller than for PVA.

Table 2

Enthalpy of the process of melting $\Delta \mathrm{H}[\mathrm{J} / \mathrm{g}]$ of PVA and PVA containing $1 \%, 3 \%$ and $5 \%$ of collagen

\begin{tabular}{|l|l|}
\hline Specimen & $\Delta \mathrm{H}[\mathrm{J} / \mathrm{g}]$ \\
\hline PVA & 27.74 \\
\hline PVA $+1 \%$ collagen & 22.62 \\
\hline PVA $+3 \%$ collagen & 20.67 \\
\hline PVA $+5 \%$ collagen & 23.94 \\
\hline Collagen & 15.45 \\
\hline
\end{tabular}

The area of the crystalline melting point is usually used to deduce the amount of 
crystallinity in the PVA sample. By a comparison of values for the heat fusion we can compare the crystallinity of the specimens. The amount of crystallinity in PVA containing $1 \%, 3 \%$ and $5 \%$ of collagen is little big smaller than the amount of crystallinity for pure PVA. One can say that small amount of collagen in PVA causes disorder between polymer chains of polymer and leads to decrease of crystallinity.

In order to assess the influence of collagen on crystallization temperature of PVA the specimens were heated with a rate $200^{\circ} \mathrm{C} / \mathrm{min}, 100^{\circ} \mathrm{C} / \mathrm{min}, 50^{\circ} \mathrm{C} / \mathrm{min}$ and $20^{\circ} \mathrm{C} / \mathrm{min}$ to melt polymer film, and later on they were cooled with the same rate. The DSC curves of PVA crystallization, obtained with cooling rate $200^{\circ} \mathrm{C} / \mathrm{min}$, have been presented in Figure 2.

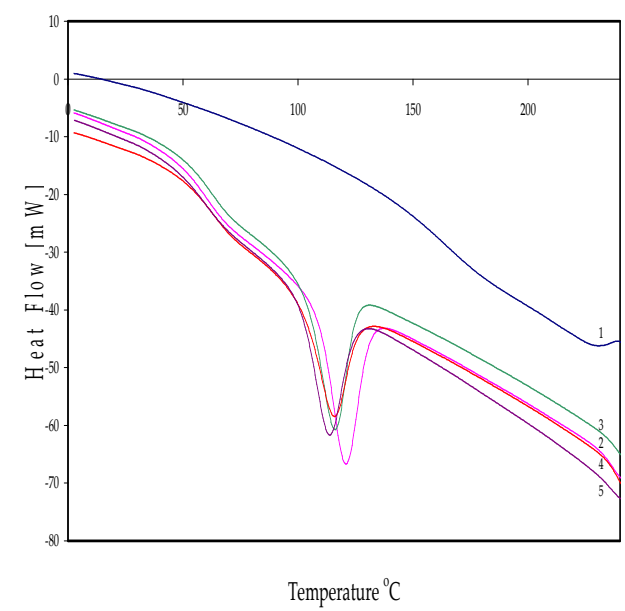

Fig. 2. DSC curves of PVA and PVA containing collagen after cooling from $250^{\circ} \mathrm{C}$ with cooling rate $200^{\circ} \mathrm{C} / \mathrm{min}$ (1-collagen, 2- PVA, 3- PVA containing $1 \%$ of collagen, 4 - PVA containing $3 \%$ of collagen, 5 - PVA containing $5 \%$ of collagen)

As one can see the crystallization temperature is different for pure PVA and for PVA containing collagen. For pure collagen film we have not observed a crystallization peak. The crystallization temperatures of PVA and PVA containing $1 \%, 3 \%$ and $5 \%$ of collagen have been presented in Table 3. For pure PVA we observed a peak of crystallization at $121^{\circ} \mathrm{C}$, whereas for PVA containing 1\% of collagen a wide peak was observed at $116^{\circ} \mathrm{C}$. For PVA containing $3 \%$ and $5 \%$ of collagen a crystallization peak was observed at 116 and $113^{\circ} \mathrm{C}$, respectively

Table 3

The crystallization temperature of PVA and PVA containing $1 \%, 3 \%$ and $5 \%$ of collagen

\begin{tabular}{|c|c|c|c|c|}
\hline Specimen & 200 & $\begin{array}{c}\text { Cifter cooling } \\
100\end{array}$ & $\begin{array}{c}\text { temperature } \\
\text { rate }\left[{ }^{\circ} \mathrm{C} / \mathrm{min}\right]\end{array}$ & {$\left[{ }^{\circ} \mathrm{C}\right]$} \\
\hline Collagen & - & - & - & 20 \\
\hline PVA & 121 & 129 & 135 & 140 \\
\hline $\begin{array}{c}\text { PVA + 1\% } \\
\text { collagen }\end{array}$ & 116. & 127 & 135 & 145 \\
\hline $\begin{array}{c}\text { PVA+ 3\% } \\
\text { collagen }\end{array}$ & 116 & 123 & 130 & 135 \\
\hline $\begin{array}{c}\text { PVA+ 5\% } \\
\text { collagen }\end{array}$ & 113. & 123 & 130 & 133 \\
\hline
\end{tabular}

The DSC curves of PVA crystallization, obtained with cooling rate $100^{\circ} \mathrm{C} / \mathrm{min}$, have been presented in Figure 3.

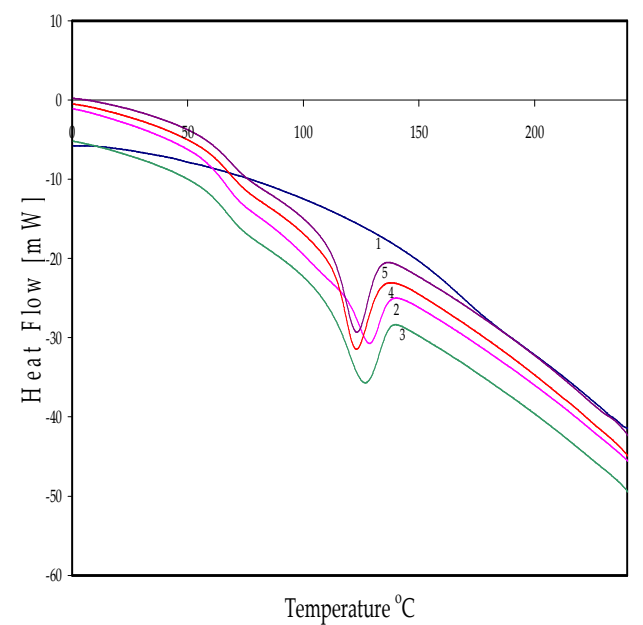

Fig. 3. DSC curves of PVA and PVA containing collagen after cooling from $250^{\circ} \mathrm{C}$ with cooling rate $100^{\circ} \mathrm{C} / \mathrm{min}$ (1-collagen, 2- PVA, 3- PVA containing $1 \%$ of collagen, 4- PVA containing $3 \%$ of collagen, 5- PVA containing $5 \%$ of collagen)

Again one can see that the crystallization temperature is different for pure PVA and for PVA containing collagen. The crystallization temperatures of PVA and PVA containing $1 \%, 3 \%$ and $5 \%$ of collagen have been presented in Table 3 . For pure PVA we observed a peak of 
crystallization at $129^{\circ} \mathrm{C}$, whereas for PVA containing $1 \%$ of collagen a wide peak was observed at $127^{\circ} \mathrm{C}$. For PVA containing $3 \%$ and $5 \%$ of collagen a crystallization peak was observed at $123^{\circ} \mathrm{C}$. Collagen does not crystallize after melting up to $250{ }^{\circ} \mathrm{C}$ and immediate cooling up to $20^{\circ} \mathrm{C}$. One can say that during cooling of PVA in melting state in the presence of small amount of collagen the crystallization process occurs slower than for pure melt PVA. In melting state collagen molecules can easily penetrate PVA molecules and molecular interactions may occur. Crystallization temperature depends on cooling rate of the specimens (Figure 4 and Figure 5).

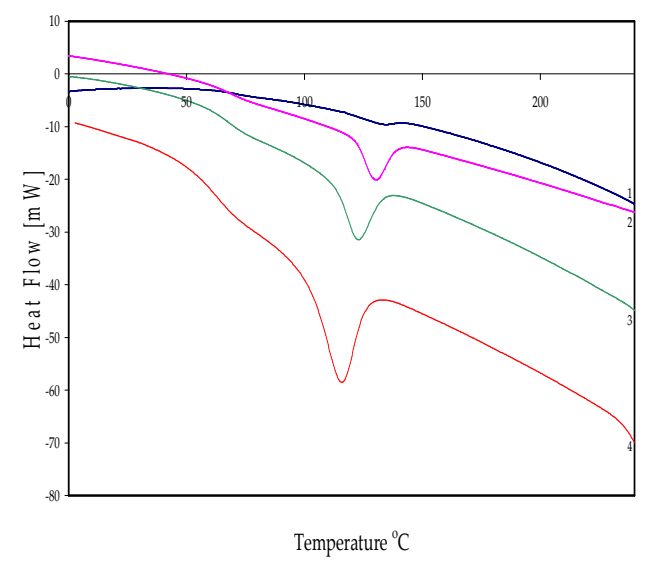

Fig. 4. DSC curves of PVA containing 3\% of collagen after cooling from $250^{\circ} \mathrm{C}$ with different cooling rate. $\left(1-20^{\circ} \mathrm{C} / \mathrm{min}, \quad 2-50^{\circ} \mathrm{C} / \mathrm{min}, \quad 3-100^{\circ} \mathrm{C} / \mathrm{min}\right.$, $4-$ $\left.200^{\circ} \mathrm{C} / \mathrm{min}\right)$

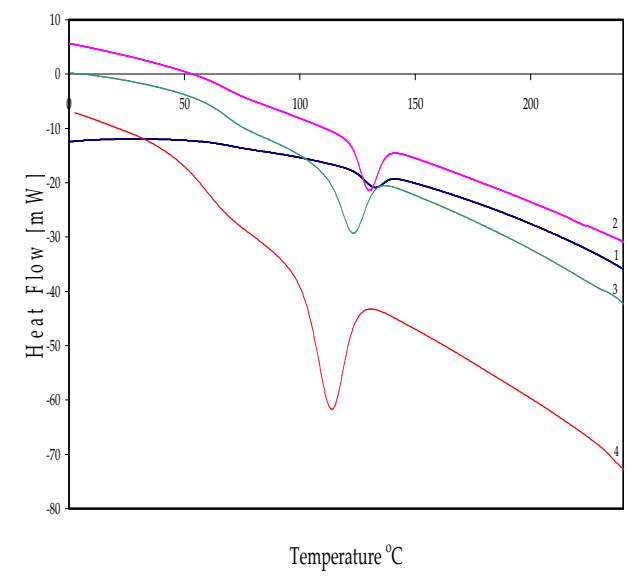

Fig. 5. DSC curves of PVA containing 5\% of collagen after cooling from $250^{\circ} \mathrm{C}$ with different cooling rate. $\left(1-20^{\circ} \mathrm{C} / \mathrm{min}, \quad 2-50^{\circ} \mathrm{C} / \mathrm{min}, \quad 3-100^{\circ} \mathrm{C} / \mathrm{min}, \quad 4-\right.$ $\left.200^{\circ} \mathrm{C} / \mathrm{min}\right)$
As can be clearly seen from Figs. 4-5 and the Table 3, for slow cooling rate $\left(20^{\circ} \mathrm{C} / \mathrm{min}\right)$ the crystallization temperature of PVA is bigger $\left(140^{\circ} \mathrm{C}\right)$ than for fast cooling rate (for cooling rate $200^{\circ} \mathrm{C} / \mathrm{min}$ the crystallization temperature was $121^{\circ} \mathrm{C}$ ). However, for all cooling rates applied in our studies, for PVA in melting state in the presence of small amount of collagen the crystallization process occurs slower than for pure melt PVA.

\section{Conclusions}

The melting temperature of poly(vinyl alcohol) PVA in the presence of 1\%,3\% and $5 \%$ of collagen is little big bigger than for pure PVA. Small amount of collagen in PVA increases melting temperature probably due to hydrogen bonding between PVA and collagen. Collagen contains several side groups capable to form hydrogen bonds with $\mathrm{OH}$ group of PVA.

The amount of crystallinity in PVA containing $1 \%, 3 \%$ and $5 \%$ of collagen is little big smaller than for pure PVA. Small amount of collagen in PVA causes disorder between polymer chains of polymer and leads to decrease of crystallinity.

During cooling of PVA in melting state in the presence of small amount of collagen the crystallization process occurs slower than for pure melt PVA.

\section{ACKNOWLEDGEMENTS}

Financial support from the Ministry of Science (MNII, Poland) Grant No. N N507 3495325 is gratefully acknowledged.

\section{REFERENCES}

[1] B.J. Holland, J.N. Hay, „The dependence of nonvolatile residue formation in nylon 6 and nylon 6,6 during thermal degradation on hydrogen bonding in the melt", Polymer, 42, 2001, p. 6775-6783.

[2] M. Krumova; D. López; R. Benavente, C. Mijangos, J.M. Pereña, „Effect of crosslinking on the mechanical and thermal properties of poly(vinyl alcohol)", Polymer, 41, 2000, p. 9265-9272.

[3] A.M.A. El-Sayed, E.E. Abdel-Hady, "Effect of temperature on g-irradiated poly(vinyl alcohol) studied by positron annihilation “, Polym. Deg. Stab. , 47, 1995, p. 339-341. 
[4] B.J. Holland, J.N. Hay, "The thermal degradation of poly(vinyl acetate) measured by thermal analysisFourier transform infrared spectroscopy ", Polymer, 43, 2002, p. 2207-221.

[5] G. Paradossi, F. Cavalieri, E. Chiessi, C. Spagnoli, M.K. Cowman., "Poly(vinyl alcohol) as versatile biomaterial for potential biomedical Application", J. Mater. Sci.: Mater. in Med., 14, 2003, p. 687-691.

[6] M.A. Khan, S.K. Bhattacharia, M.A. Kader, K. Bahari, „Preparation and characterization of ultra violet (UV) radiation cured bio-degradable films of sago starch/PVA blend", Carbohydr. Polym., 63, 2006, p.500-506.

[7] B. Sarti, M. Scandola, „Viscoelastic and thermal properties of collagen/poly(vinyl alcohol) blends", Biomaterials, 16, 1995, p. 785-792.

[8] A. Sionkowska, M.Wisniewski, J. Skopinska, "Photochemical stability of collagen/poly (vinyl alcohol) blends", Polym. Deg. Stab., 83, 2004, p. 117125.

[9] C.H. Chen, F.Y. Wang, C.F. Mao, W.T. Liao, C.D. Hsieh, "Studies of chitosan: II. Preparation and characterization of chitosan/poly(vinyl alcohol)/ gelatin ternary blend films", Int. J Biol. Macromol. 43, 2008, p. 37-42.

[10] K.H. Lee, D.H. Baek, C.S. Ki, Y.H. Park, "Preparation and characterization of wet spun silk fibroin/poly(vinyl alcohol) blend filaments", Int. J. Biol. Macromol. 41, 2007, p. 168-172.

[11] D.M. Fernandes, A.A. Winkler Hechenleitner, A.E. Job, E. Radovanocic, E.A. Gómez Pineda, "Thermal and photochemical stability of poly(vinyl alcohol)/modified lignin blends", Polym. Deg. Stab., 91, 2006, p. 1192-1201.

[12 ] Van der Rest R., Garrone M., "Collagen family of proteins", FASEB J., 5, 1991, p. 2814-2819.

[13] A. Sionkowska, A. Kamińska, C. A. Miles, A. J. Bailey, "The effect of UV radiation on the structure and properties of collagen", Polimery 6, 2001, p. 379452. 